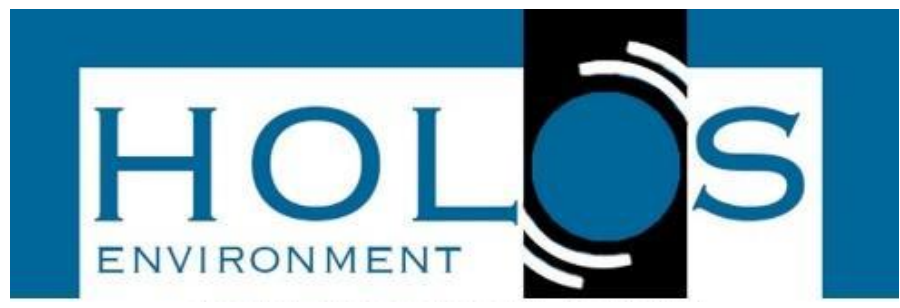

\title{
RECUPERAÇÃO AMBIENTAL DAS ÁREAS DE EXTRAÇÃO DE BENTONITA NA REGIÃO DE BOA VISTA/PB
}

\section{ENVIRONMENTAL RECOVERY OF THE BENTONITE EXTRACTION AREAS IN THE BOA VISTA/PB REGION}

\author{
Gerson Ferreira da Silva ${ }^{1}$
}

Artigo recebido em: 14/11/2019 e aceito para publicação em: 20/01/2020.

DOI: http://dx.doi.org/10.14295/holos.v20i1.12360

Resumo: A ocorrência de argila bentonítica cálcica, comumente conhecida como bentonita, está concentrada no estado da Paraíba nas cidades de Cubati e principalmente em Boa Vista, onde apresenta o maior volume de reserva e exploração de argila nobre como a verde, chocolate e chocobofe. Tendo seu uso na indústria de pelotização, fundição, perfuração de poços, até areia para gatos. Localmente, as jazidas situam-se em áreas planas, apresentando inversão na morfologia do relevo, quando, em função das profundidades das cavas. A recuperação da área com o uso de material orgânico, tem como objetivo o retorno do sítio degradado a uma forma de utilização, de acordo com um plano pré-estabelecido para uso de solo, visando a obtenção de estabilidade do meio ambiente. Reconstituindo as cavas mineradas, através da deposição do material oriundo do capeamento, e principalmente pela recomposição florística local, com utilização de espécies nativas.

Palavras-chave: Bentonita. Argila. Recuperação ambiental. Mineração.

Abstract: The Occurrence of Calcium bentonite clay also known as bentonite is concentrated in Paraíba in Cubati city and mainly in Boa Vista where shows the biggest volume reserve and exploitation of noble clay, like the green, chocolate and chocobofe. Having its use in pellotizing industry, casting, well drilling and even in cat litter. Locally the deposits are in flat áreas showing inversion in relief morphology, when due to the depths of the pits. The área recovery using organic material has as objective the return of the degraded place to a form of use in according to a pre-established project for the using of the soil. Aiming the obtaining of stability of the environment. Reconstituting the mined pits through the deposition of the material coming from the capping, and mainly by the local floristic recomposition, with the use of native species.

Keywords: Bentonite. Clay. Environment recovery. Mining.

\section{INTRODUÇÃO}

Geologicamente, bentonita foi definida por Ross e Sahronnon (1926) como sendo uma rocha constituída essencialmente por um argilomineral montmorilonítico,

\footnotetext{
${ }^{1}$ Doutorando em Engenharia de Minas (UFRGS), Porto Alegre/RS. E-mail: (gmineracao@hotmail.com)
} 
formada pela desvitrificação e subsequente alteração química de um material vítreo, de origem ígnea, usualmente um tufo ou cinza vulcânica (MENEZES et al., 2009).

As principais jazidas de bentonita em operação no Brasil estão localizadas no município de Boa Vista, estado da Paraíba. Existem outros depósitos de bentonita, como no município de Vitória da Conquista, estado da Bahia. A Bentonit União Nordeste, situada em Boa Vista/PB, produz exclusivamente bentonita do tipo ativada. Em 2014, a produção bruta de bentonita no Brasil foi de 405.169 t, o que representou um aumento de apenas $0,4 \%$ em relação a 2013. Os estados produtores foram Paraíba $(60,8 \%)$ e Bahia $(39,2 \%)$. Houve aumento de produção na Bahia e redução na Paraíba. Os principais usos da bentonita são: aglomerante em areias de fundição, pelotização de minério de ferro, perfuração de poços de petróleo, captação de água, terra higiênica para gatos, indústria química e farmacêutica e clarificantes (PORTO E ARANHA, 2002).

Os depósitos de argila bentoníticas de Boa Vista/PB encontram-se associados a derrames basálticos olivínicos, constituindo uma sequência vulcano-sedimentar de distribuição restrita. Os estudos realizados nestas áreas permitem atestar o modelo de sequência de deposição já descrita por Caldasso (1965) em considerações sobre as argilas bentoníticas de Boa Vista, segundo o qual, os sedimentos basais iniciamse por arenitos conglomeráticos que gradam superiormente para arenitos e siltitos. Segundo Gopinath (1981) a intercalação do ambiente e o modo de sedimentação deste depósito, deve ser feito através de estudos das estruturas sedimentares, textura, geometria ou forma do depósito e a variação litológica dos sedimentos.

$\mathrm{Na}$ atividade de exploração de bentonita verifica-se pouca geração de resíduos, geralmente, da remoção do capeamento superficial, e da retirada de camadas estéreis intercaladas ao pacote de minério argiloso.

Especificamente na região de Boa Vista/PB, a agressão ao meio ambiente é restrita ao desmatamento, aos finos em suspensão, e principalmente na topografia, que não retorna à configuração original. Sendo necessário fazer a recuperação das cavas com preenchimento de estéreis, e terraplanagem do relevo, com objetivo de fazer a recuperação ambiental.

As minas Juá I e II, localizadas no sítio lajes, no município de Boa Vista, estado da Paraíba foram selecionados para o desenvolvimento deste trabalho devido a sua importância para a economia local, e principalmente pela necessidade de uma 
recuperação ambiental adequada das cavas existentes, contribuindo para o bem-estar e melhoria da qualidade de vida.

\section{MATERIAL E MÉTODOS}

A pesquisa foi desenvolvida inicialmente por um levantamento bibliográfico referente a recuperação ambiental na mineração, e posteriormente realizado os trabalhos de campo. A etapa de leitura foi direcionada especificamente para literatura que aborda os aspectos que envolvem a recuperação de áreas degradadas por atividades de mineração.

Foram abordados: a análise de conceitos sobre argila bentonita, a vegetação que abrange o cariri da região de Boa Vista-PB, as médidas e as estratégias utilizadas nas ativididades de recuperação, métodos e técnicas desenvolvidas ao longo dos anos para melhoria da recuperação das cavas exploradas, e principalmente textos relacionado ao emprego dos solos, nesse processo de revitalização das áreas mineradas.

Os levantamentos de campo tiveram como objetivo estabelecer uma uma parceria com o orgão ambiental (SUDEMA-PB), a visitação a algumas empresas da região de pesquisa que trabalham com a mesma atividade, e principalmente para escolha e estudo de duas áreas específicas que foram mineradas, denominadas de Juá I e Juá II.

\subsection{Localização da área de estudo}

A área de recuperação ambiental (Figura 1) está situada à cerca de $10 \mathrm{~km}$ a oeste da sede do Município de Boa Vista/PB, e em torno de $70 \mathrm{Km}$ da cidade de Campina Grande/PB, na Fazenda denominada Lajes. O acesso é feito, partindo da cidade de Campina Grande/PB, pela Rodovia BR-230 sentido cidade de Soledade/PB, percorrendo cerca de $32 \mathrm{Km}$ pela BR-230 chega-se a Praça do Meio do Mundo, tomando-se a partir desta a rodovia BR-412. Na altura do $\mathrm{km} \mathrm{20,} \mathrm{na} \mathrm{cidade} \mathrm{de} \mathrm{Boa}$ Vista, toma-se à estrada secundária, que dá acesso ao Município de Cabaceiras e nas imediações da propriedade de nome Fazenda Urubu (cerca de 05Km), toma-se à estrada Municipal e após 06 km chega-se à área de recuperação ambiental. 
Figura 1 - Localização das áreas de recuperação ambiental

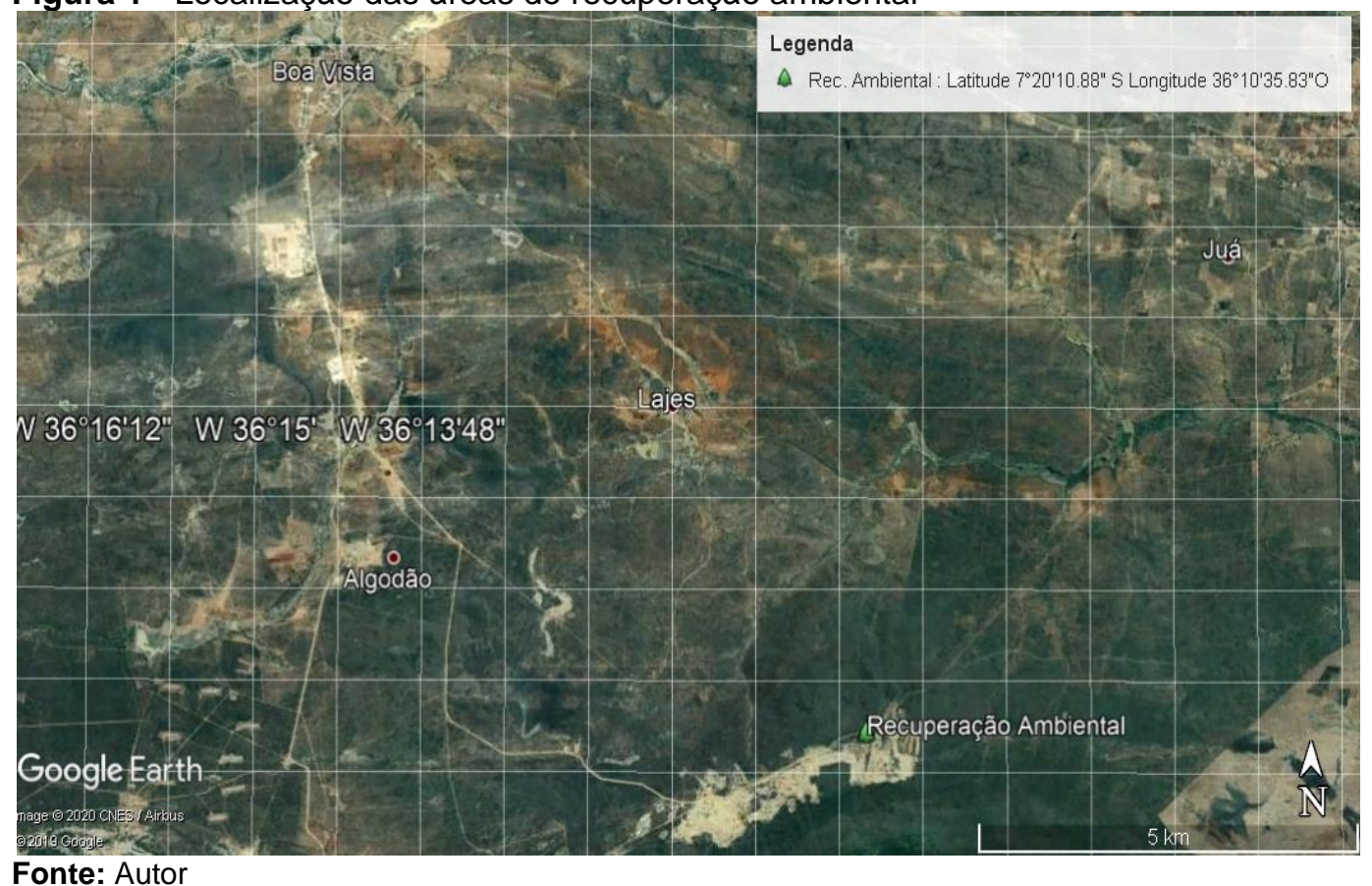

\subsection{Recuperação das Áreas}

Quanto ao processo de recuperação ambiental desenvolvido neste estudo, foi realizado em áreas de argila bentonita mineradas na região de Boa Vista-PB. O processo consistiu incialmente em preparação das mudas, fechamento da cava, compactação e nivelamento das áreas (Figura 2) a serem recuperadas, deposição do material orgânico (Figura 3), e por fim o plantio das mudas nos setores preparados. Depois da cava ser preenchida, nivelada, adubada e plantada, a área foi cercada e isolada por um determinado tempo para a devida recuperação ambiental.

Para início das atividades de plantio foram feitas visitas de campo as áreas de recuperação ambiental das Mina Juá I, e Juá II para coletar informações, amostras e realizar os primeiros levantamentos dos trabalhos a serem desenvolvidos. Foram determinadas as dimensões das cavas a serem recuperadas, a quantidade de mudas por $\mathrm{m}^{2}$ de área, e os espaçamentos entre cada espécie nativa.

Os trabalhos de reabilitação das áreas foram desenvolvidos seguindo as etapas abaixo:

\subsubsection{Recuperação física}


Preenchimento e nivelamento das cavas tornando o relevo nestes locais, suave ondulado;

- Terraplenagem parcial do terreno, eliminando os focos degradativos, devendo ser deixadas preferencialmente valas de drenagem;

- Implantação do sistema de drenagem natural em sulcos no entorno da cava, para evitar a erosão.

\subsubsection{Recuperação biológica}

- Estabilização dos taludes, rampas e encostas com vegetação herbácea (gramíneas) ou similar da caatinga;

- Revegetação do entorno da área com espécies arbustivo-arbóreas nativas, visando eliminar o impacto visual;

- Regularização topográfica do terreno (terraplenagem) com auxílio de equipamentos mecanizados, objetivando a eliminação de pilhas de material estéril e focos de erosão, nas cavas rasas;

- Cercamento da área de plantio para evitar a entrada de animais a exemplo de bovinos e ovinos.

\subsubsection{Processo de plantio}

As mudas utilizadas na recuperação das áreas foram produzidas em um viveiro de uma das empresas da região. Alguns tipos de espécies foram disponibilizados pela Faculdade de Agronomia da UFPB, em Areia/PB.

$\mathrm{O}$ transporte das mudas até as áreas de pesquisa, foi realizado em um carro do tipo "pick up", devidamente cobertas por lona para evitar o ressecamento das mesmas pelo sol e pelo vento.

\subsubsection{Coveamento para o plantio das mudas}

Ao furar as covas teve-se a preocupação com o tamanho dos sacos plásticos, onde as mudas são produzidas, e que geralmente possuem $18 \times 24 \mathrm{~cm}$. As covas foram cavadas um pouco mais que isso, o Plantio das mudas foi realizado manualmente. 


\subsubsection{Adubação}

Inicialmente pensou-se em usar uma mistura de terra, esterco, e, se possível, adubo químico. Mas devido aos custos, e da possibilidade de desenvolver essa pesquisa com o material que anteriormente seria descartado, empregou-se o solo orgânico, oriundo da etapa de decapeamento. De um modo geral é recomendado o adubo fosfatado Super Simples. Na quantidade 100 quilos por hectare, o que daria uma média de 90 gramas por cova, dentro de espaçamentos 4 × 4 e/ou 5 x 5 metros. O adubo denominado solo orgânico, foi colocado no fundo da cova e misturado à terra. Também procurou evitar que o adubo entrasse em contato com as raízes, pois poderia "queimá-las".

\subsubsection{Disposição das mudas no campo e densidade de mudas}

As mudas foram dispostas aleatoriamente no campo utilizando um espaçamento variável entre $4 \times 4 \mathrm{~m}, 5 \times 5 \mathrm{~m}$ ou $6 \times 6 \mathrm{~m}$ para as espécies arbóreo/arbustivas, e adensadamente para as espécies herbáceo/rasteiras. Estas últimas, em curva de nível, quando plantadas nos taludes.

\subsubsection{Plantio}

O plantio foi realizado no período chuvoso, rigorosamente seguindo uma sequência heterogenia, com o propósito de preservar a biodiversidade local, utilizando-se as espécies recomendadas e/ou outras nativas que melhor se adaptarem ao local. As mudas foram colocadas nas covas junto com os torrões que protegem as raízes. Ao retirar os saquinhos, deverão ser preservados os torrões. 
Figura 2 - Nivelamento das áreas

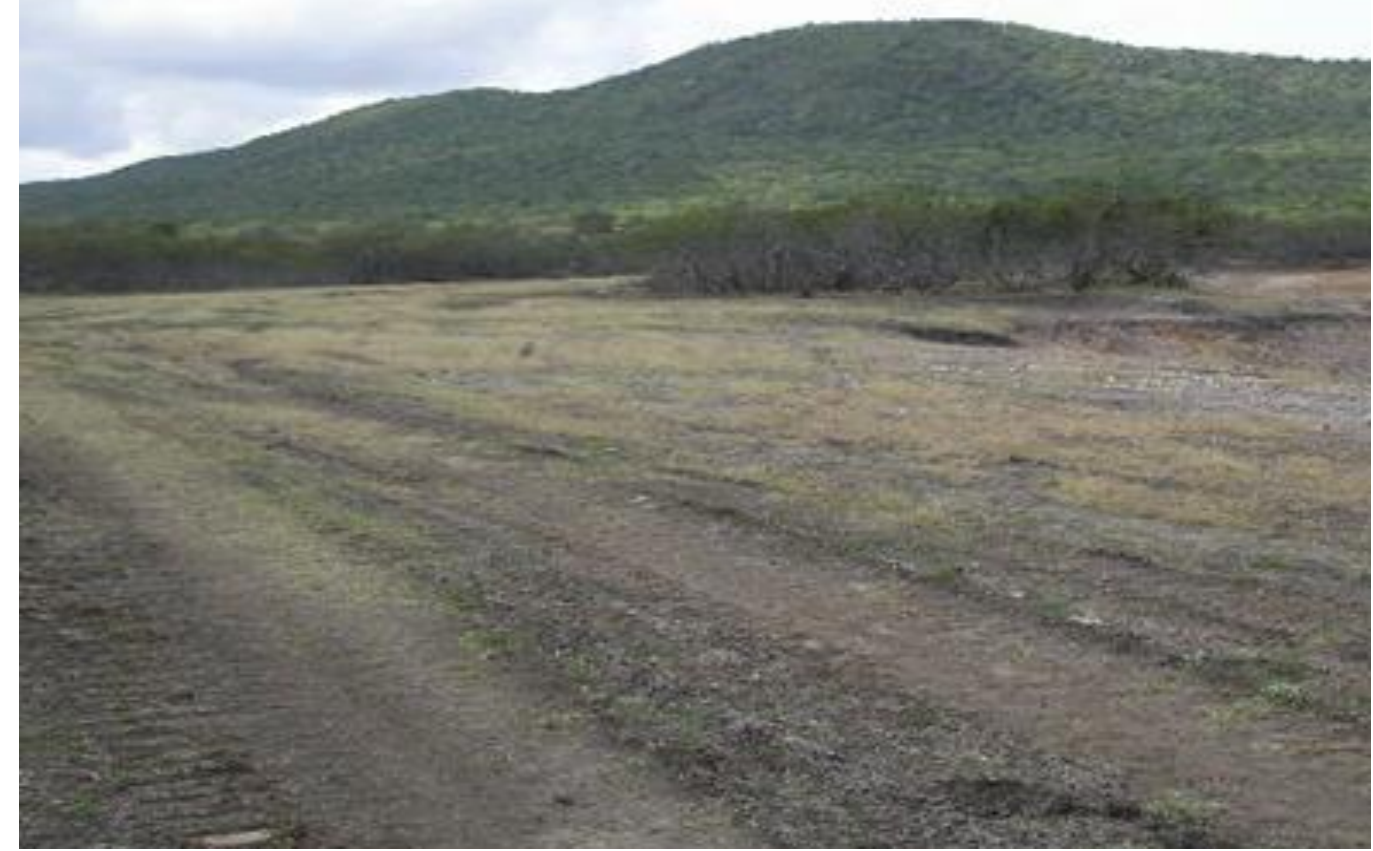

Fonte: Autor

As mudas foram produzidas em viveiro de uma das empresas envolvida no projeto de pesquisa, e o plantio das espécies como a macambira (Bromélia laciniosa) virá das mudas mais jovens, da parte externa do "ninho ou nicho" que elas formam.

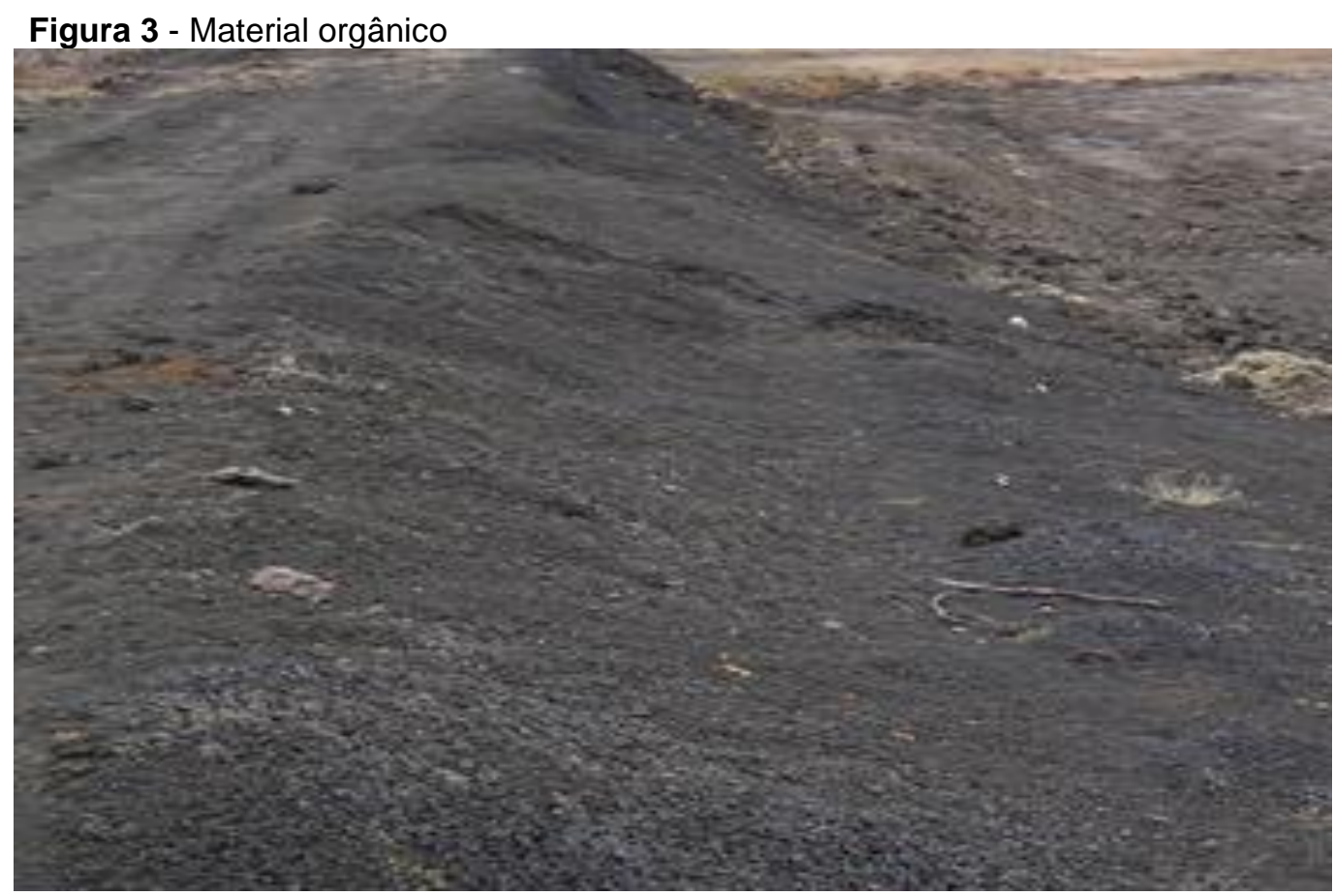


Fonte: Autor

No que se refere aos xique-xique (Pilosocereus gounellei), mandacaru (Cereus giganteus), palmatória (Opuntia Leucotricha) e facheiro (Cereus squamosus), as mudas foram retiradas de hastes novas do tronco destes cactáceos, tomando o cuidado para extraí-las rente a esse tronco. No caso das umburanas (Cecropia sp) e pião (Jatropha molíssima), as mudas são cortadas de galhos, tipo estaca, procurando as mais ricas em brotos.

\section{RESULTADOS E DISCUSSÃO}

Para a seleção das espécies levou-se em consideração os fatores ambientais já conhecidos da região, (clima, escassez de água, baixa fertilidade de solo). Desta forma, deu-se preferência à utilização de espécies arbóreo/arbustivas e herbáceo/rasteiras, conforme Tabela 1.

$\mathrm{Na}$ Tabela 1, é apresentado as espécies nativas, as quantidades de mudas, e o local do plantio das espécies do tipo cactáceas (macambira, xique-xique, mandacaru, facheiro, coroa de frado, palmatória e palma), do tipo arbustivo (pião), e do tipo arbóreo (mulungu, umburana). A quantidade para cada tipo de mudas corresponde a 100 unidades, distribuídas na área de plantio do projeto de estudo. Tendo, seu uso nos taludes para contensão da erosão, e em superfícies planas e suavemente onduladas.

Tabela 1 - Tipos de mudas usadas no plantio de recuperação ambiental

\begin{tabular}{lcc}
\hline \multicolumn{1}{c}{ NOME } & $\begin{array}{c}\text { MINA JUÁ I e MINA JUÁ II } \\
\text { No MUDAS }\end{array}$ & LOCAL DE PLANTIO \\
\hline Macambira/Bromélia laciniosa & 100 & contensão de erosão \\
Mandacaru/Cereus giganteus & 100 & contensão de erosão \\
Xique-xique/Pilosocereus gounellei & 100 & contensão de erosão \\
Facheiro/Cereus squamosus & 100 & Áreas planas e suaves \\
Palmatória/Opuntia leucotrincha & 100 & Áreas planas e suaves \\
Coroa de frade/Melocactus zehntneri & 100 & Áreas planas e suaves \\
Palma/ Opuntia ficus indica & 100 & Áreas planas e suaves \\
Umburana/ Cecropia sp & 100 & Áreas planas e suaves \\
Catingueira / Caesalpinea bracreosa & 100 & Áreas planas e suaves \\
Pião/ Jatropha mollissima & 100 & Áreas planas e suaves \\
\multicolumn{1}{c}{ Total } & $\mathbf{1 0 0 0}$ & - \\
\hline
\end{tabular}

Fonte: Autor 
A quantidade de espécies empregada no projeto da Mina Juá I, apresenta uma relação de 1 muda para cada $4 \mathrm{~m}^{2}$ de área. As mudas foram replantadas de maneira aleatória no campo, utilizando um espaço variável de no máximo 4x4m para espécies arbóreo/arbustivo, e não foi usado adensamento para as espécies herbáceo/rasteiras.

A razão entre área/número de mudas foi baseada no tamanho da área a ser recuperada (Tabela 2), e a quantidade de mudas utilizadas para o plantio. O volume de mudas plantadas na respectiva área de recuperação ambiental apresenta um espaço vazio entre cada espécie. Neste caso, o número de mudas usadas na recuperação do Juá I foi modificado, fazendo um ajusto para 1 muda/ entre 2 e $3 \mathrm{~m}^{2}$ para espécies arbóreo, lembrando que não foi feito uma aproximação maior das espécies herbáceo/rasteiras.

Tabela 2 - Extensão das áreas recuperadas

\section{DIMENSÕES DAS ÁREAS DE RECUPERAÇÃO}

\begin{tabular}{ccc} 
Mina & Área Plantada $\left(\mathbf{m}^{2}\right)$ & Volume de Massapê (ton) \\
\hline Mina Juá I & $50 \times 100=5.000$ & Não usou massapê \\
Mina Juá II & $50 \times 100=5.000$ & 60 \\
\hline
\end{tabular}

Fonte: Autor

A área reservada a Mina Juá I foi preenchida geralmente pelos cactáceos (macambira, xique-xique, mandacaru, facheiro, coroa de frade e palmatória), do arbustivo (pião), e do arbóreo (umburana), em uma cava recém-fechada, e sua topografia nivelada.

Em seguida, foi realizado o processo de plantação sem uso do solo orgânico oriundo do decapeamento de onde se extraiu a bentonita.

Esta área de recuperação sem adubação do solo fértil foi uma das primeiras experiências no processo de minimizar a degradação ambiental na região de lavra de bentonita, onde no qual, conforme registro fotográfico (Figura 4) consta-se a pobreza da recuperação da vegetação. Neste caso, cria-se um microecossistema inadequado para refúgio e abrigo para os remanescentes faunísticos. 
Figura 4 - Área recuperada sem uso de material orgânico

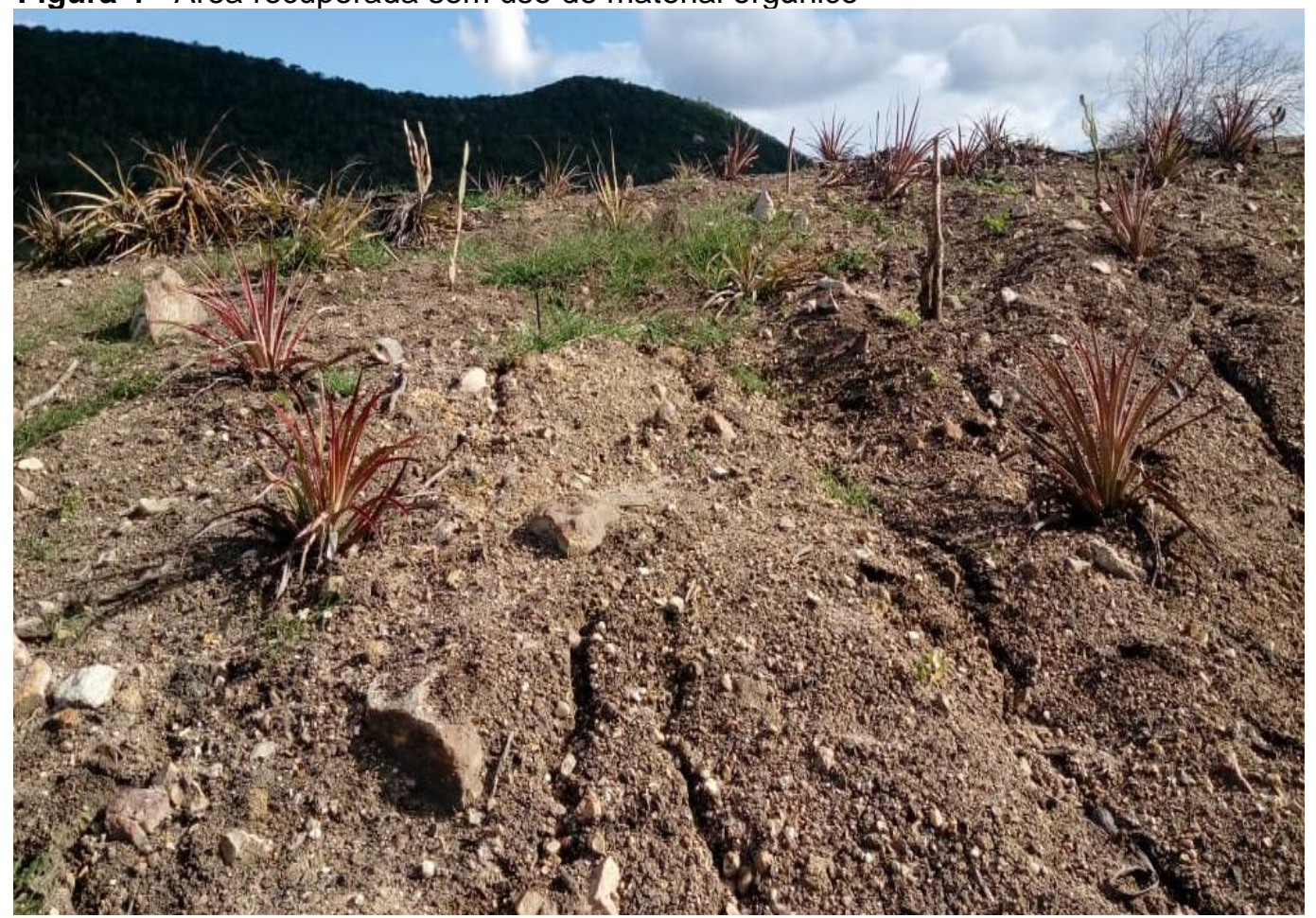

Fonte: Autor

A quantidade de espécie nativa e outras utilizadas no Mina juá II apresenta uma relação de 1 muda $/ 5 m^{2}$ (Tabela 1 e 2). As mudas foram dispostas aleatoriamente no campo utilizando um espaçamento variável de $6 \times 6 \mathrm{~m}$ para as espécies arbóreo/arbustivas, e adensadamente para as espécies herbáceo/rasteiras. Estas últimas, em curva de nível, quando plantadas nos taludes. Essa razão foi mensurada considerando o tamanho da área a ser destinada ao plantio, e a quantidade de mudas usadas para serem plantadas (Tabela 1). O volume de mudas plantadas na respectiva área de recuperação ambiental demonstra um espaço vazio entre cada espécie. Neste caso, o número de plantio usado nesta recuperação do Juá II foi modificado, fazendo um ajusto para 1 muda $/ 3 \mathrm{~m}^{2}$ para espécies arbóreo e uma aproximação maior das espécies herbáceo/rasteiras.

A área reservada a Mina Juá II é normalmente preenchida pelos cactáceos (macambira, xique-xique, mandacaru, facheiro, coroa de frade e palmatória), do arbustivo (pião), e do arbóreo (umburana), em uma cava recém-fechada, e sua 
topografia nivelada. Em seguida esta área recebeu o solo orgânico, procedimento inovador paras as áreas de lavra de argila, nesta região.

Esse material é oriundo do decapeamento de onde se extraiu a bentonita. Este solo orgânico, denominado de massapê é depositado e espalhado, e posteriormente recebe as mudas para serem plantadas, realizando-se os trabalhos da recuperação, e o resultado pode ser visto através da Figura 5.

Figura 5 - Vegetação da área recuperada com uso de material orgânico

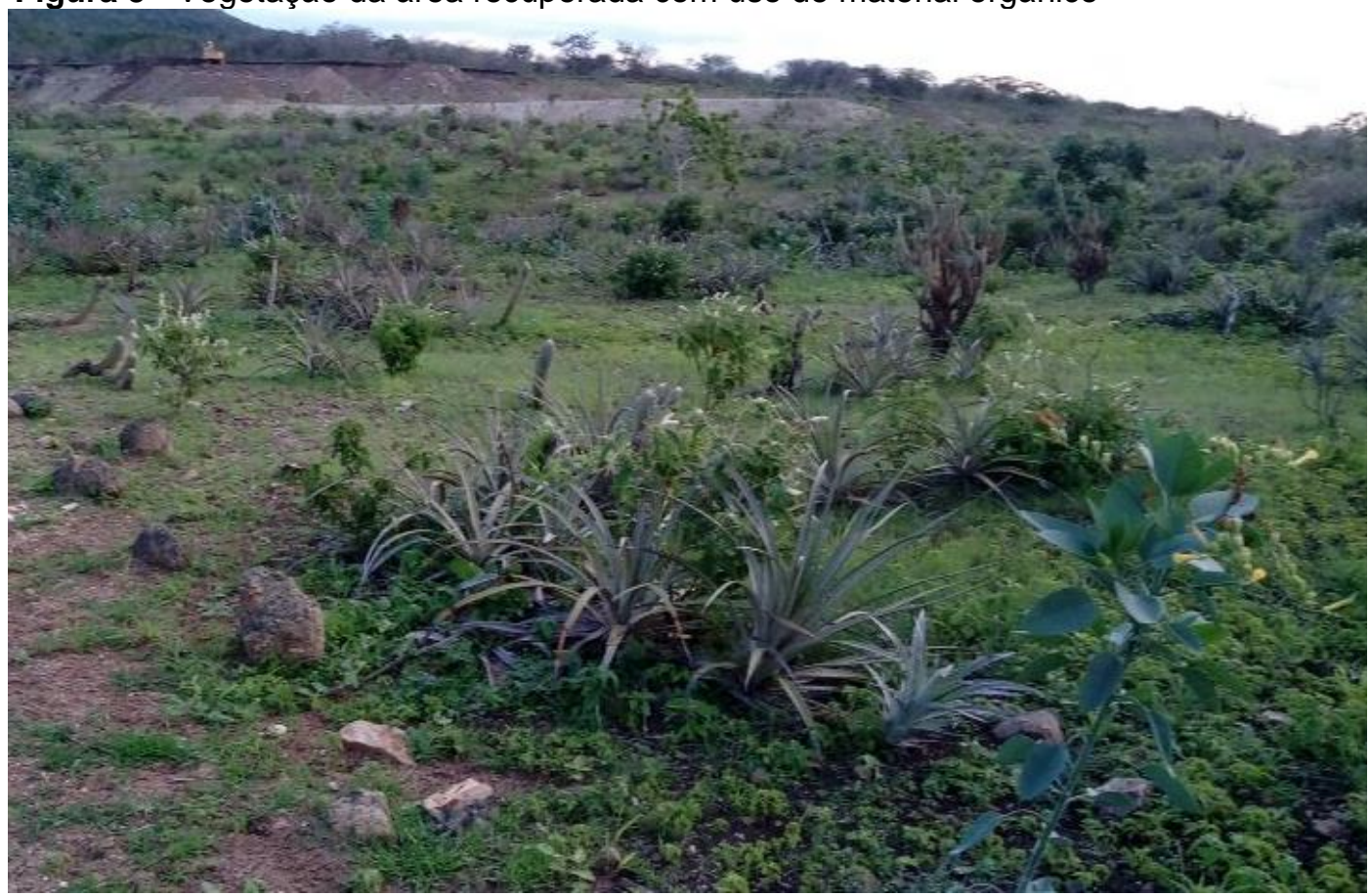

Fonte: Autor

\section{CONCLUSÕES}

O processo de recuperação das áreas de lavra de argila da região de Boa Vista$\mathrm{Pb}$, tem apresentado ao longo dos anos deficiência em sua revitalização, tendo áreas com erosão e ausência de espécies da fauna e flora da caatinga. O trabalho desenvolvido recentemente, com o uso de material orgânico, conhecido como massapê, foi empregado pela necessidade de realizar algumas melhorias. Assim, esse estudo permitiu a retomada da vegetação nativa, melhorou o aspecto visual das áreas, e possibilitou o reaparecimento de alguns animais da região.

\section{REFERÊNCIAS}


CALDASSO, A.L.S. Jazida de Argila de Boa Vista, Pb, Bol. Soc. Bras. Geol., 1979.

DNPM. Departamento Nacional de Produção Mineral. Sumário Mineral, Bentonita, 2015.

GOPINATH, T. R.; SCHUSTER, H.D.; SCHUCKMANN, W.K., 1981. Modelo de Ocorrência e Gênese da Argila Bentonítica de Boa Vista, Campina Grande, Paraíba. Revista Brasileira de Geociência, São Paulo, v. 11, n. 3, p. 185-192, 1981. https://doi.org/10.25249/0375$\underline{7536.1981185192}$

IBAMA. Instituto Nacional do Meio Ambiente e dos Recursos Naturais Renováveis. Manual de recuperação de áreas degradadas pela mineração. Técnicas de revegetação, 1990. $94 \mathrm{p}$.

MENEZES, R.R.; SOUTO, P.M.; SANTANA, L.N.L.; NEVES, G.A.; KIMINAMI, R.H.G.A; FERREIRA, H.C. Argilas Bentoníticas de Cubati, Paraíba, Brasil: caracterização físicamineralógica. Cerâmica, v. 55, n. 334, 2009. https://doi.org/10.1590/S0366$\underline{69132009000200008}$ 